\title{
Conversion of Plastic Surgery meeting abstract presentations to full manuscripts: a brazilian perspective
}

\section{Conversão dos resumos apresentados em congressos de Cirurgia Plástica em manuscritos completos: uma perspectiva brasileira}

\author{
Rafael Denadal, AsCbC-SP'; André Silveira Pinho'; Hugo Samartine Júnior'; Rodrigo Denadal'; Cassio Eduardo Raposo-Amaral ${ }^{1}$.
}

\begin{abstract}
A B S T R A C T
Objective: to assess the conversion rate of Plastic Surgery meeting abstract presentations to full manuscript publications and examine factors associated with this conversion. Methods: we assessed the abstracts presented at the 47th and 48th Brazilian Congresses of Plastic Surgery by cross-referencing with multiple databases. We analyzed the Abstracts' characteristics associated with full manuscript publications. Results: of the 200 abstracts presented, 50 abstracts were subsequently published in full, giving the conference a conversion rate of 25\%. The mean time to publish was $15.00 \pm 13.75$ months. In total, there were $4.93 \pm 1.63$ authors per abstract and $67.8 \pm 163$ subjects per abstract; $43.5 \%$ of the abstracts were of retrospective studies; $69 \%$ comprised the plastic surgery topics head and neck, and chest and trunk, and $88.5 \%$ had no statistical analysis. Overall, $80 \%$ of the manuscripts were published in plastic surgery journals, $76 \%$ had no impact factor and $52 \%$ had no citations. Bivariate and multivariate analyses revealed the presence of statistical analysis to be the most significant $(p<0.05)$ predictive factor of conversion of abstracts into full manuscripts. Conclusion: the conversion rate found from this bibliometric research appeared a bit lower than the conversion trend of international plastic surgery meetings, and statistical analysis was a determinant of conversion success.
\end{abstract}

Keywords: Meeting abstracts. Manuscripts. Publications

\section{INTRODUCTION}

B razil's scientific production has increased substantially, reaching an average growth rate of $10.7 \%$ per year ${ }^{1}$. However, as presentations of abstracts at different Brazilian medical meetings have been accompanied by a relatively low conversion rate into full manuscript publications in peer-reviewed, indexed journals ${ }^{2-8}$, this scientific growth could potentially be higher. Therefore, a continuous analysis of the conversion rate should be performed to encourage members of each academic society to publish full manuscripts ${ }^{2-8}$.

In this context, there has been no data about the conversion rate from Brazilian Plastic Surgery meetings, although international Plastic Surgery meetings have been analyzed ${ }^{9-13}$. In addition, we are not aware of any investigation of possible predicting factors for the publication of plastic surgery meeting abstracts as full manuscripts ${ }^{9-13}$.
Thus, the purposes of this quantitative, descriptive, bibliometric study were to assess the conversion rate of Brazilian plastic surgery meeting abstracts into full peer-reviewed, indexed manuscripts and to examine possible predicting factors of this conversion. We hypothesized that despite increased diffusion of the necessity of full manuscript publications within the Brazilian plastic surgery community ${ }^{14,15}$, the conversion rate after Brazilian plastic surgery meeting presentations would be inferior than the international plastic surgery trends ${ }^{9-13}$.

\section{METHODS}

\section{Identification of abstracts}

Two independent authors identified and analyzed the abstracts through examination of the online supplements published by the Brazilian Society of Plastic Surgery (Sociedade Brasileira de Cirurgia Plástica - SBCP) from the $47^{\text {th }}$ and $48^{\text {th }}$ Brazilian Congresses of

1 - SOBRAPAR Hospital, Institute of Plastic and Craniofacial Surgery, Campinas, Sao Paulo State, Brazil. 
Plastic Surgery, held in 2010 and 2011, respectively. We recorded the following quantitative bibliometric data for each individual abstract: year (2010 or 2011; periods 1 and 2, respectively); number of authors (1-3, 4-5, or >6); plastic surgery topic (head and neck; chest and trunk; extremities; general; or others) according to designation in the meeting programs; number of included subjects (1, 2-10, 11-50, 51-100, or >101); presence of statistical analysis; and study designs (randomized clinical trial, systematic review, simple review, prospective study, retrospective study, case series, case reports, and others) $)^{2-8,16-18}$.

\section{Full manuscript publication search}

We identified the publications in peerreviewed journals by a standardized searching of the Medline (PubMed), ISI Web of Knowledge, SciELO, Lilacs, and Google Scholar databases through March 2015. We used the last name and the first letter of the first name of the first author of the abstracts. If we dis not find an exact match or if there were no results to a search, we repeated the process using the second and the last authors of the abstracts. If the result included no publication or several publications with the same author, we applied an additional criterion, such as another author or keywords from the title or text of the abstract to expand or simplify the search. Whenever we retrieveda peer-reviewed manuscript, we compared the abstract information with those of the full publication to establish whether they matched in accordance with the stringent criteria previously used $^{16-18}$.

For each matching publication, we recorded the following data: period between the abstract presentation and the publication ( $<12$ months; 12-36 months; >36 months); journal name; database indexing journal (ISI Web of Knowledge and Medline; Medline; SciELO; or Lilacs); impact factor of the journal according to the Thompson Reuters Journal Citation Report ${ }^{\circledR}$ on the date of publication; language of the publication (English, Portuguese, or English/Portuguese); and the number of citations of the manuscript according to
Google Scholar and ISI Web of Knowledge (if indexed journal) $)^{6,9,12,16-18 .}$

\section{Statistical analyses}

For the descriptive analysis, we used the mean and standard deviations for numerical variables and percentages for categorical variables. We defined the conversion rate as the ratio between the number of subsequently published articles in peer-reviewed journals and the total number of abstracts presented at the scientific meetings ${ }^{18}$. We performed intra- and interperiod (period 1 versus period 2) comparisons. We used Analysis of Variance, Equality of Two Proportions, Paired Student's T, Chi-Square, and Confidence Interval for the Mean tests for statistical comparisons. We performed bivariate and multivariate logistic regression analyses to determine which independent abstract variables (number of authors, number of subjects, plastic surgery topic, presence of statistical analysis and study designs) were significant predictors for the conversion of abstracts into full manuscripts (dependent variable). We also calculated theinterobserver reliability between the two authors who collected all of the data. We performed all analyses using the software program Statistical Package for Social Science (SPSS version 20.0 for Windows, Chicago, IL, USA). We considered as significant values with a confidence interval of $95 \%(p<0.05)$.

\section{RESULTS}

We included two hundred meeting abstracts in this bibliometric study, with an excellent interobserver agreement (all values between 0.86 and 0.99 ) for all evaluated abstracts and manuscript variables.

\section{Meeting abstract characteristics}

Overall, there was a significant (all $p<0.05$ ) predominance in the proportion of abstracts including: more than six authors; 11-50 subjects/abstract; head and neck, and chest and trunk plastic surgery topics; absence of statistical analysis; and retrospective study design. The inter-period analyses revealed a significant 
Table 1. Characteristics of Plastic Surgery meeting abstracts ( $n=200)$.

\begin{tabular}{|c|c|c|c|c|}
\hline Abstrat variables & $\begin{array}{l}2010-2011 \\
(n=200)\end{array}$ & $\begin{array}{c}2010 \\
(n=100)\end{array}$ & $\begin{array}{c}2011 \\
(n=100)\end{array}$ & $p$-value** \\
\hline Authors/abstract $\mathrm{M} \pm \mathrm{SD}$ & $4.93 \pm 1.63$ & $5.09 \pm 1.56$ & $4.76 \pm 1.69$ & 0.153 \\
\hline $1-3$ n (\%) & $40(20)$ & $18(18)$ & $22(22)$ & 0.480 \\
\hline $4-5$ n (\%) & $52(26)$ & $27(27)$ & $25(25)$ & 0.747 \\
\hline$>6 \mathrm{n}(\%)$ & $108(54)$ & $55(55)$ & $53(53)$ & 0.777 \\
\hline$p$-value * & $<0.001$ & $<0.001$ & $<0.001$ & - \\
\hline 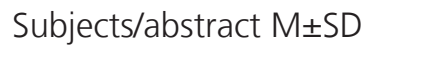 & $67.8 \pm 163$ & $68.4 \pm 130$ & $67.2 \pm 193$ & 0.963 \\
\hline $1 \mathrm{n}(\%)$ & $22(13.3)$ & $4(4.7)$ & $18(22.5)$ & $<0.001$ \\
\hline $2-10$ n (\%) & $41(24.7)$ & $21(24.4)$ & $20(25)$ & 0.931 \\
\hline $11-50$ n (\%) & $61(36.7)$ & $40(46.5)$ & $21(26.2)$ & 0.007 \\
\hline $51-100$ n (\%) & $18(10.8)$ & $7(8.1)$ & $11(13.8)$ & 0.245 \\
\hline$>101$ n (\%) & $24(14.5)$ & $14(16.3)$ & $10(12.5)$ & 0.489 \\
\hline$p$-value * & $<0.001$ & $<0.001$ & $<0.001$ & - \\
\hline \multicolumn{5}{|l|}{ Plastic surgery topic n (\%) } \\
\hline Head and neck & $76(38)$ & $37(37)$ & $39(39)$ & 0.771 \\
\hline Chest and trunk & $62(31)$ & $29(29)$ & $33(33)$ & 0.541 \\
\hline Extremities & $33(16.5)$ & $23(23)$ & $10(10)$ & 0.013 \\
\hline General & $25(12.5)$ & $11(11)$ & $14(14)$ & 0.521 \\
\hline "Other" & $4(2)$ & $0(0)$ & $4(4)$ & 0.043 \\
\hline$p$-value * & $<0.001$ & $<0.001$ & $<0.001$ & - \\
\hline \multicolumn{5}{|l|}{ Statistical analysis n (\%) } \\
\hline Present/Absent & 23 (11.5) / 177 (88.5) & $14(14) / 86(86)$ & $9(9) / 91(91)$ & 0.268 \\
\hline$p$-value * & $<0.001$ & $<0.001$ & $<0.001$ & - \\
\hline \multicolumn{5}{|l|}{ Study designs n (\%) } \\
\hline Randomized clinical Trial & $2(1)$ & $1(1)$ & $1(1)$ & 1.000 \\
\hline Systematic review & $1(0.5)$ & $0(0)$ & $1(1)$ & 0.316 \\
\hline Simple review & $15(7.5)$ & $7(7)$ & $8(8)$ & 0.788 \\
\hline Prospective study & $15(7.5)$ & $5(5)$ & $10(10)$ & 0.179 \\
\hline Retrospective study & $87(43.5)$ & $54(54)$ & $33(33)$ & 0.003 \\
\hline Case series & $43(21.5)$ & $23(23)$ & $20(20)$ & 0.606 \\
\hline Case reports & $22(11)$ & $4(4)$ & $18(18)$ & 0.002 \\
\hline Other & $15(7.5)$ & $6(6)$ & $9(9)$ & 0.421 \\
\hline$p$-value * & $<0.001$ & $<0.001$ & $<0.001$ & - \\
\hline \multicolumn{5}{|c|}{ Published as full manuscript n (\%) } \\
\hline Yes/No & $50(25) / 150(75)$ & $32(32) / 68(68)$ & $18(18) / 82(82)$ & 0.022 \\
\hline$p$-value * & $<0.001$ & $<0.001$ & $<0.001$ & - \\
\hline
\end{tabular}

M, Mean; SD, standard deviation; *, intra-period comparisons; **, inter-period comparisons; -, not applicable; Note 1: sample size not stated in 34 abstracts due to study designs. 
(all $p<0.05$ ) increase (period $1<$ period 2 ) in the proportion of abstracts with one subject/abstract, case reports, and "other" study designs; and a significant (all $p<0.05$ ) decrease (period $1>$ period 2 ) in the proportion of abstracts with 11-50 subjects/abstract, extremities topics, and retrospective study design (Table 1).

\section{Full manuscript characteristics}

Overall, there were 50 (25\%) matching full manuscripts, and a significant (all $p<0.05$ ) predominance in the proportion of abstracts published as full manuscripts within 12 months after meeting presentations, manuscripts in Portuguese, manuscripts published in plastic surgery journals, journals indexed in the SciELO database, journals without an impact factor, and manuscripts without citations. The interperiod analyses revealed a significant (all $p<0.05$ ) reduction (period $1>$ period 2 ) in the proportion of abstracts converted into full manuscripts and manuscripts in English/Portuguese languages (Table 2).

\section{Bivariate and multivariate analyses}

Bivariate analysis revealed that abstracts with 1-3 and 4-5 authors/abstract, one subject/abstract, general plastic surgery topic, and case reports were significantly (all $p<0.05$ ) less converted into full manuscripts. Bivariate and multivariate analyses demonstrated that the presence of statistical analysis was the most significant (all $p>0.05$ ) predictive factor of conversion success (Table 3 ).

\section{DISCUSSION}

Abstract presentations at scientific meetings are an integral component of medical research, in which investigators can share their results with others and meeting attendees may obtain new information ${ }^{18,19}$. Although acceptance of an abstract by a scientific meeting is prestigious, ideally abstracts should be followed by a full manuscript publication in peerreviewed journals for several reasons: key novel findings and useful information should also be available to the general scientific community who did not participate in the meetings; abstracts alone have many defects, inaccuracies, and only preliminary data; abstracts have been devoid of information that is needed for evaluating validity and reliability; and abstracts are accepted for presentations without a peer-review process or have been reviewed less thoroughly than what is typical of journal manuscripts ${ }^{18,19}$. In addition, adverse consequences of research inaccessibility include: unnecessary duplication, delays in the dissemination of advances in patient-care strategies, harm to patients, waste of limited resources, and loss of (trust in) scientific integrity ${ }^{20}$. In fact, research ethical obligations require the appropriate dissemination and publication of all research outcomes ${ }^{21}$, and empirical evidence indicates the existence of research dissemination bias, as published studies tend to be systematically different from unpublished studies ${ }^{22}$.

It is also noteworthy that the conversion rate may be regarded as an indicator of the scientific level of a certain society's meeting ${ }^{12}$. Interestingly, however, a considerable proportion of medical meeting abstracts have never been published as full manuscripts ${ }^{18}$. In Brazil, the publication rates from different medical fields were previously established ${ }^{2-8}$. To the best of our knowledge, there has been no similar research from a Brazilian plastic surgery perspective, although there are recent bibliometric plastic surgery data ${ }^{14,15}$.

Therefore, in response to an identified gap in the national plastic surgery literature, we quantified conversion rates from the major Brazilian plastic surgery meeting. Our rationale for evaluating this particular meeting was threefold: first, it is the most important scientific plastic surgery event in Brazil; second, it is applicable to a wide plastic surgery audience, as it is general in nature; and third, Brazilian Portuguese was the primary language of presentation. Plastic surgeons are invited to submit scientific abstracts that are reviewed for relevance and scientific value by a scientific committee called that Department of Scientific Events of SBCP. Our data is mainly from a plastic surgery perspective, but our bibliometric research is also important for the overall Brazilian scientific 
Table 2. Characteristics of plastic surgery full manuscripts $(n=50)$.

\begin{tabular}{|c|c|c|c|c|}
\hline Manuscript variables & $\begin{array}{c}2010-2011 \\
(n=50)\end{array}$ & $\begin{array}{l}2010 \\
(n=32) \\
\end{array}$ & $\begin{array}{l}2011 \\
(n=18) \\
\end{array}$ & $p$-value** \\
\hline $\begin{array}{l}\text { Time from presentation to publication } \\
\text { (months) } M \pm S D\end{array}$ & $15.00 \pm 13.75$ & $15.48 \pm 13.76$ & $14.11 \pm 14.09$ & 0.737 \\
\hline < 12 months $\mathrm{n}(\%)$ & $29(58)$ & $17(53.1)$ & $12(66.7)$ & 0.352 \\
\hline $12-36$ months $n(\%)$ & $19(38)$ & $13(40.6)$ & $6(33.3)$ & 0.610 \\
\hline > 36 months n (\%) & $2(4)$ & $2(6.3)$ & $0(0)$ & 0.279 \\
\hline$p$-value * & $<0.001$ & $<0.001$ & $<0.001$ & - \\
\hline \multicolumn{5}{|l|}{ Publication language n (\%) } \\
\hline English & $13(26)$ & 7 (21.9) & $6(33.3)$ & 0.343 \\
\hline Portuguese & $25(50)$ & $13(40.6)$ & $12(66.7)$ & 0.063 \\
\hline English/Portuguese & $12(24)$ & $12(37.5)$ & $0(0)$ & 0.002 \\
\hline$p$-value * & $<0.001$ & $<0.001$ & $<0.001$ & - \\
\hline \multicolumn{5}{|l|}{ Journals n (\%) } \\
\hline Brazilian Journal of Plastic Surgery & $22(44)$ & $14(43.8)$ & $8(44.4)$ & 0.651 \\
\hline Plastic and Reconstructive Surgery & $5(10)$ & $3(9.3)$ & $2(11.1)$ & 0.817 \\
\hline Brazilian Journal of Craniomaxillofacial Surgery & $5(10)$ & $4(12.5)$ & $1(5.6)$ & 0.451 \\
\hline Catarinense Medicine Archives & $5(10)$ & $2(6.3)$ & $3(16.7)$ & 0.224 \\
\hline Aesthetic Plastic Surgery & $4(8)$ & $4(12.5)$ & $0(0)$ & 0.124 \\
\hline Journal of the Brazilian College of Surgeons & $3(6)$ & $3(9.3)$ & $0(0)$ & 0.187 \\
\hline Brazilian Journal of Head and Neck Surgery & $2(4)$ & $2(6.3)$ & $0(0)$ & 0.287 \\
\hline Others & $4(8)$ & $0(0)$ & $4(22.2)$ & $<0.05$ \\
\hline$p$-value * & $<0.001$ & $<0.001$ & $<0.001$ & - \\
\hline \multicolumn{5}{|l|}{ Database indexing journal n (\%) } \\
\hline Medline and ISI & $13(26)$ & $7(21.9)$ & $6(33.2)$ & 0.282 \\
\hline Medline & $3(6)$ & $2(6.2)$ & $1(5.6)$ & 0.200 \\
\hline SciELO and Lilacs & $1(2)$ & $0(0)$ & $1(5.6)$ & 0.159 \\
\hline SCIELO & $19(38)$ & $14(43.8)$ & $5(27.8)$ & 0.369 \\
\hline Lilacs & $14(28)$ & $9(28.1)$ & $5(27.8)$ & 0.873 \\
\hline$p$-value * & $<0.001$ & $<0.001$ & $<0.001$ & - \\
\hline \multicolumn{5}{|l|}{ Impact factor $\mathrm{n}(\%)$} \\
\hline Present / Absent & $13(26) / 36(74)$ & $7(21.9) / 25$ (78.1) & 6 (33.3) / 12 (66.7) & 0.343 \\
\hline$p$-value * & $<0.001$ & $<0.001$ & 0.046 & - \\
\hline \multicolumn{5}{|l|}{ Manuscript citations } \\
\hline 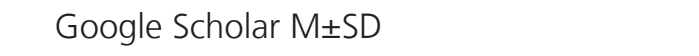 & $1.78 \pm 3.17$ & $2.18 \pm 3.70$ & $1.00 \pm 1.58$ & 0.275 \\
\hline Yes / No n (\%) & $24(48) / 26(52)$ & $\begin{array}{c}14(43.8) / 18 \\
(56.2)\end{array}$ & 10 (55.6) / 8 (44.4) & 0.933 \\
\hline$p$-value * & 0.110 & 0.218 & 0.218 & - \\
\hline ISI Web of Knowledge $M \pm S D$ & $0.40 \pm 1.14$ & $0.52 \pm 1.35$ & $0.18 \pm 0.53$ & 0.326 \\
\hline Yes / No n (\%) & $8(16) / 42(84)$ & $6(18.8) / 26(81.2)$ & 2 (11.1) / 16 (88.9) & 0.558 \\
\hline$p$-value * & $<0.001$ & $<0.001$ & $<0.001$ & - \\
\hline
\end{tabular}

M, Mean; SD, standard deviation; *, intra-period comparisons; **, inter-period comparisons; -, not applicable. 
Table 3. Bivariate and multivariate analyses for conversion rate.

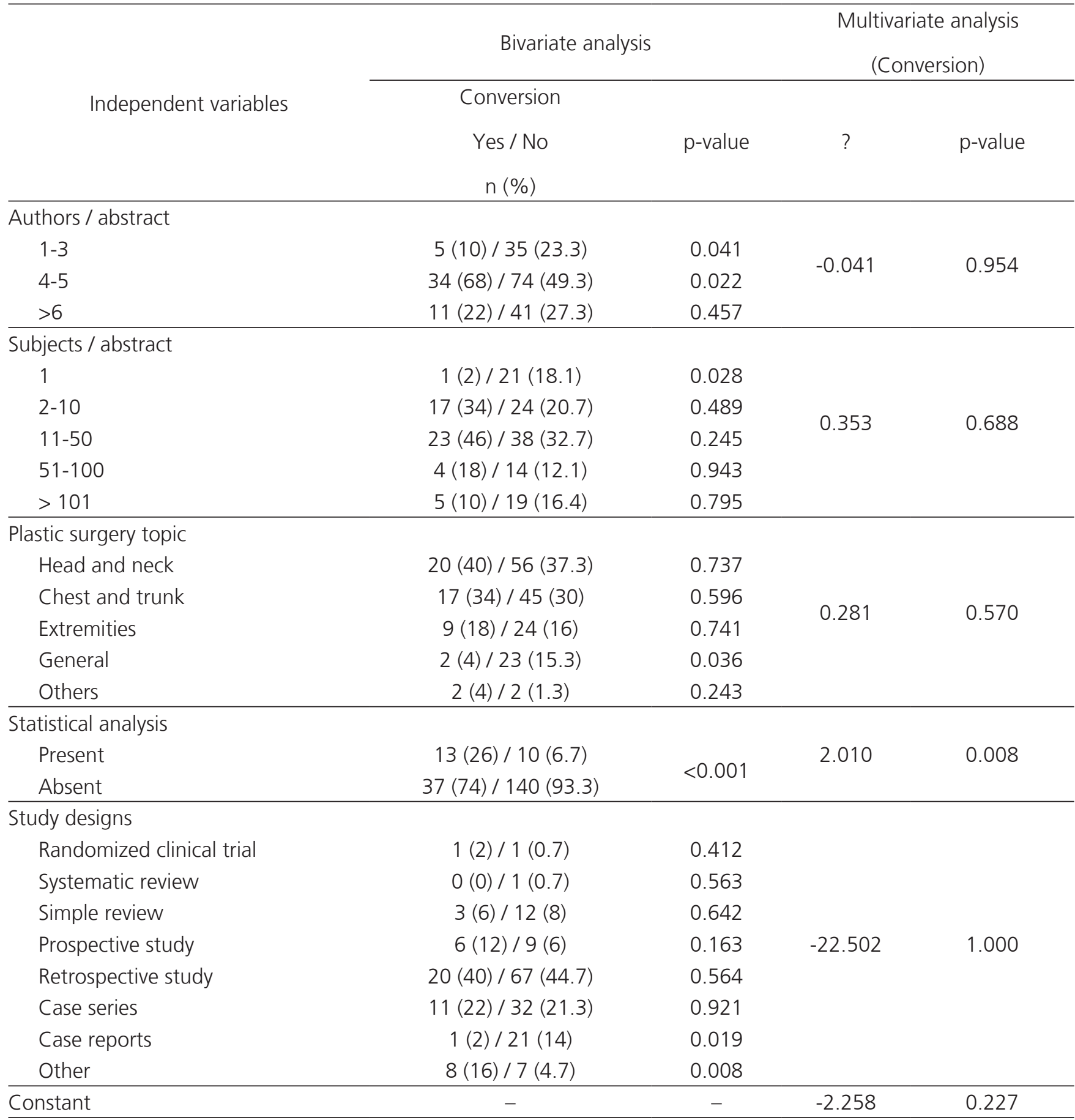

M, mean; SD, standard deviation; -, not applicable.

community, as it allows a quantitative assessment of the relative contribution from Brazilian plastic surgery investigators to the scientific scenario. It also permits the initiation of a critical reflection on actual scientific production, with potential modifications of planning by the specialty society, academic community, and governmental actions for research induction, financing, human resources training, among others, as has been proposed in other medical fields $s^{2,7,16,17}$.

We showed an overall conversion rate of $25 \%$, ranging from $32 \%$ to $18 \%$ in meetings held in 2010 and 2011, respectively. A Cochrane systematic review with meta-analysis ${ }^{18}$ from 29,729 abstracts revealed a mean conversion rate of $44.5 \%$, with a wide range of 
conversion rates across medical specialties. Conversion rates following Brazilian scientific meetings also vary according to the assessed medical field, including: general surgery $(2.6 \%)$, trauma $(2.9 \%)$, angiology and vascular surgery $(6.32 \%)$, cancer $(16.9 \%)$, orthopedic $(26.6 \%)$, and urology $(39-51.3 \%)^{2-8}$. In addition, particularly from a plastic surgery perspective, our initial hypothesis proved to be right, as the overall Brazilian plastic surgery conversion rate was inferior to most of the prior international plastic surgery conversion rates (38.7\%-63.7\% $)^{9-13}$ and was only superior to the British Association of Plastic, Reconstructive, and Aesthetic Surgeons meeting conversion rate $(20 \%)^{9-13}$.

The abstract characteristics (number of subjects, number of authors, and plastic surgery topics) are in conformity with the previous bibliometric plastic surgery meeting trends ${ }^{9-13}$. Moreover, some of the characteristics of the manuscripts are different from previous published trends ${ }^{9-13}$, with most abstracts being published in journals without an impact factor and only indexed in SciELO. More than $43 \%$ of the abstracts were published in the Brazilian Journal of Plastic Surgery (Revista Brasileira de Cirurgia Plástica), the official journal of the SBCP. Previous reports ${ }^{9-13}$ also highlight that abstracts presented at meetings organized by scientific societies are preferentially submitted for publication to the official journals.

We also investigated independent abstract factors that may predict full manuscript publication, as they have not been previously investigated in the plastic surgery meeting literature ${ }^{9-13}$. Bivariate analysis revealed that abstracts with 1-3 and 4-5 authors/abstract and general plastic surgery topics were significantly less converted in full manuscripts. The increase in the number of authors per article has been evident in scientific literature, and may reflect a progressive complexity in academic work ${ }^{23}$, which are potentially more likely to be published, and the increasing focus on subspecialtization of plastic surgery ${ }^{24}$ may partially explain these findings. However, as we have not ascertained the connection, future research should test these hypotheses.
We also showed that the presence of statistical analysis was a significant determinant for conversion success, as exhibited in different societies' meetings ${ }^{16,17}$. Although the provision of appropriate statistical tests is an important quality criteria of abstract reporting ${ }^{16}$, details about statistical testing were provided in only $11.5 \%$ of the evaluated abstracts; and interestingly, many retrospective studies (the major study design in our report) had a potential sample of patients, but no statistical analysis was applied. Therefore, identifying the right statistical test as an essential component of research design and ensuring that data are correctly obtained with sufficient power to address the original research hypothesis ${ }^{25}$ should be the target of plastic surgeons in the future.

In addition, our bivariate analysis showed that abstracts with only one subject and case reports were significantly less converted into full manuscripts, whereas the study design was not significant in predicting the conversion of abstracts into full manuscripts in the multivariate analysis. Although one can assume that studies with increased methodological rigor, such as randomized clinical trials and prospective studies are likely to have higher conversion rates than case series and case reports, there are mixed results regarding the study design of meeting abstracts as a determinant factor of conversion success ${ }^{16-18}$. As we also showed an increase of case reports and a decrease of retrospective studies, efforts to increase publishing research with more thorough research methods in Brazilian plastic surgery must be promoted as evidencebased medicine achieves greater acceptance within the plastic surgery community 14,15

We found that $75 \%$ of abstracts presented at the Brazilian Congress of Plastic Surgery remained unpublished after four years. The reasons why some scientific meeting abstracts remain unpublished are not entirely clear and probably act in a complex multifactorial format ${ }^{19,26}$. Rejection by journals may be a cause of nonpublication; however, as most of the unpublished studies have not been submitted to journals, non-publication of many studies was directly caused by failure of authors 
to write and submit it to journals ${ }^{26}$. A recent systematic review ${ }^{19}$ revealed that among different factors (e.g., "lack of resources," "publication not an aim," "low priority," "incomplete study," and "trouble with co-authors"), "lack of time" was the most frequently reported reason and the most important reason for not subsequently publishing abstracts as full-length manuscripts. The plastic surgery literature ${ }^{27}$ has demonstrated that a median of 177 hours is needed to take a retrospective study from idea genesis to publication, and the number of authors or subjects is not correlated with the hours spent per publication, whereas different factors (e.g., medical students, residents, and data collection) were associated with more hours spent per plastic surgery publication ${ }^{27}$. As we are unable to directly address the real reasons that may have influenced non-publication of abstracts, further studies should be delineated to investigate this issue.

In this context, our data reinforced previous anecdotal perceptions that regular scientific productivity has not been the rule among Brazilian plastic surgeons ${ }^{14,15}$. In fact, Brazil was poorly ranked (number of articles and impact factor) in recent worldwide bibliometric plastic surgery analyses ${ }^{28,29}$, although the Brazilian plastic surgery community with more than 5,500 plastic surgeons and 83 plastic surgery residency programs accredited by SBCP - is among one of the biggest plastic surgery communities worldwide.

Therefore, to improve conversion rates, we need major changes in the Brazilian plastic surgery research culture. Given the necessity of disseminating all research findings, mandatory full manuscript submission for publication before meeting presentation may be considered.Although this might be a radical notion and reduce the number of abstracts submitted, the result would be an increased publication yield ${ }^{10,18}$. Senior authors and experienced research teams should be encouraged to assist junior authors and incipient scientific groups with study completion and manuscript preparation $^{10,18}$. In addition, the next generation of plastic surgeons should receive the knowledge that "an abstract is only a work in progress ${ }^{30}$," as emphasized by Dr. Joseph Murray, a Nobel laureate plastic surgeon, during the residency training process. For these culture changes, governmental, departmental and SBCP support is urgently required,for both faculties and trainees, including dedicated research time and a research infrastructure. It will be a long-term journey, but with the support of the entire Brazilian plastic surgery community, it is possible to get there.

Some inherent limitations to this study design may have influenced our results and must be considered when interpreting our findings. The variability of conversion rates may be related to the quality of meeting presentations, alterations in the criteria for abstract selection, the stringency of the publication criteria for the specialty's peer-review journals, differences of scientific profile of each specialty and medical society, and/or the inherent methodology of determining conversion rates ${ }^{2-13,16-18}$. Thus, the trend comparisons performed in our study should be interpreted with caution. Our results likely underestimate the overall Brazilian conversion rate after meeting presentations. Given the bibliometric nature of this study, there is the potential for selection bias; it is possible that the search strategy did not accurately identify all publications, although our methods of selection, inclusion, and analysis have been found in

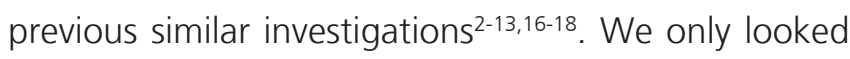
at abstracts presented at one particular plastic surgery meeting, mirroring previous studies $2-9,11-13,16,17$. Thus, it is possible that the analysis of other meetings would show different rates of Brazilian plastic surgeons' contributions. Our study is also limited by the data provided by the investigators in the abstracts, as there was no information about the type of institution involved, academic status, gender of the investigators, among others. A further caveat stems from the fact that we assessed the proportional Brazilian contribution in the form of abstracts. It is conceivable that goodquality Brazilian research throughout the years analyzed was submitted for full publication without presentation at the evaluated plastic surgery meeting. Such possibility would lead to an underestimation of 
Brazilian productivity. An additional limitation is that we only assessed quantitative aspects of the abstracts. Finally, a minimum 3-year period was fixed to allow time for publication of each meeting abstract, as the vast majority of publications appeared in the first three to four years after meeting presentations $s^{2-13,16-18}$.

\title{
R E S U M O
}

\begin{abstract}
Objetivo: avaliar a taxa de conversão de resumos apresentados em congressos de Cirurgia Plástica em publicações de manuscritos completos e examinar fatores associados a essa conversão. Métodos: resumos apresentados nos XLVII e XLVIII Congressos Brasileiros de Cirurgia Plástica foram avaliados por meio de referências cruzadas em diversos bancos de dados. Averiguaram-se as características dos resumos associadas às publicações de manuscritos completos. Resultados: dos 200 resumos apresentados, 50 foram posteriormente publicados

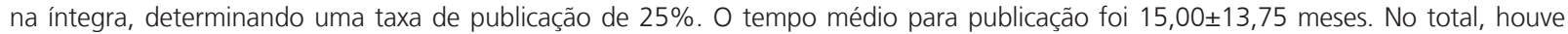

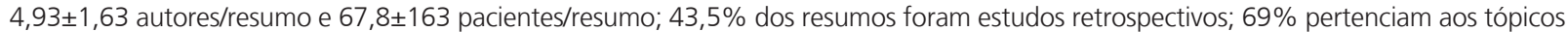
crânio, cabeça e pescoço, e tórax e tronco e 88,5\% não apresentavam análise estatística. No geral, 80\% dos manuscritos foram publicados em revistas de Cirurgia Plástica, 76\% não exibiam fator de impacto e 52\% não possuíam citações. As análises bivariada e multivariada revelaram que a presença de análise estatística foi o fator preditivo significativo $(p<0,05)$ para a conversão de resumos em manuscritos completos. Conclusão: a taxa de conversão deste estudo bibliométrico foi inferior à tendência de conversão descrita em congressos internacionais de Cirurgia Plástica, e a presença de análise estatística foi um determinante para o sucesso de conversão.
\end{abstract}

Descritores: Manuscritos. Cirurgia plástica. Publicações.

\section{REFERÊNCIAS}

1. Almeida ECE, Guimarães JA. Brazil's growing production of scientific articles--how are we doing with review articles and other qualitative indicators? Scientometrics. 2013;97(2):287-315.

2. Arap MA, Reis RB, Torricelli FCM, Masson ALS, Saad ED. Brazilian abstracts presented at the American Urological Association Annual Meetings: contribution, publication rates, and comparison with Oncology abstracts. Int baz j urol. 2014;40(6):730-7.

3. Ejnisman L, Gomes GS, Oliveira RG, Malavolta EA, Gobbi RG, Camargo OP. Publication rates of papers presented at the Brazilian Orthopedic Meeting. Acta ortop bras. 2013;21(5):285-7.

4. Andrade VA, Carpini S, Schwingel R, Calderan TR, Fraga GP. Publication of papers presented in a Brazilian Trauma Congress. Rev Col Bras Cir. 2011;38(3):172-6.

5. Oliveira LRS, Figueiredo AA, Choi M, Ferrarez CEPF, Bastos AN, Netto JMB. The publication rate of abstracts presented at the 2003 Urological Brazilian Meeting. Clinics (Sao Paulo). 2009;64(4):345-9.

6. Saad ED, Pinheiro CMA, Masson AL, Borghesi G, Hoff PM, Prisco FE. Increasing output and low publication rate of brazilian studies presented at the American Society of Clinical Oncology Annual Meetings. Clinics (Sao Paulo). 2008;63(3):293-6.
7. Yoshida WB, Holmo NF, Corregliano GT, Baldon KM, Silva NS. Indexed publications generated from abstracts of Angiology and Vascular Surgery Congresses in Brazil. J vasc bras. 2008;7(4):293-7.

8. Fernandes $F A M H$, Ventura DE, Del Grande JC. Índice de publicação dos trabalhos apresentados no XXIV Congresso Brasileiro de Cirurgia. Rev Col Bras Cir. 2003;30(5):392-5.

9. Chung KJ, Lee JH, Kim YH, Kim TG, Ha JH. How many presentations are published as full papers? Arch Plast Surg. 2012;39(3):238-43.

10. Gregory TN, Liu T, Machuk A, Arneja JS. What is the ultimate fate of presented abstracts? The conversion rates of presentations to publications over a five-year period from three North American Plastic Surgery Meetings. Can J Plast Surg. 2012;20(1):33-6.

11. Kain N, Mishra A, McArthur P. Are we still publishing our presented abstracts from the British Association of Plastic and Reconstructive Surgery (BAPRAS)? J Plast Reconstr Aesthet Surg. 2010;63(9):1572-3.

12. van der Steen LP, Hage JJ, Loonen MP, Kon M. Full publication of papers presented at the 1995 through 1999 European Association of Plastic Surgeons Annual Scientific Meetings: a systemic bibliometric analysis. Plast Reconstr Surg. 2004;114(1):113-20. 
13. Oliver DW, Whitaker IS, Chohan DP. Publication rates for abstracts presented at the British Association of Plastic Surgeons Meetings: how do we compare with other specialties? Br J Plast Surg. 2003;56(2):158-60.

14. Denadai R, Raposo-Amaral CE. The level of evidence published in a partner Journal of Plastic and Reconstructive Surgery: Revista Brasileira de Cirurgia Plástica. Plast Reconstr Surg. 2014;133(2):242e-4e.

15. Denadai R, Raposo-Amaral CE. Levels of evidence in plastic surgery: an analysis of resident involvement. J Craniofac Surg. 2014;25(4):1573-5.

16. Smith WA, Cancel QV, Tseng TY, Sultan S, Vieweg J, Dahm P. Factors associated with the full publication of studies presented in abstract form at the Annual Meeting of the American Urological Association. J Urol. 2007;177(3):1084-8; discussion 1088-9.

17. Peng PH, Wasserman JM, Rosenfeld RM. Factors influencing publication of abstracts presented at the AAO-HNS Annual Meeting. Otolaryngol Head Neck Surg. 2006;135(2):197-203.

18. Scherer RW, Langenberg P, von Elm E. Full publication of results initially presented in abstracts. Cochrane Database Syst Rev. 2007;18(2):MR000005.

19. Scherer RW, Ugarte-Gil C, Schmucker C, Meerpohl JJ. Authors report lack of time as main reason for unpublished research presented at biomedical conferences: a systematic review. J Clin Epidemiol. 2015;68(7):803-10.

20. Chan AW, Song F, Vickers A, Jefferson T, Dickersin K, Gøtzsche PC, et al. Increasing value and reducing waste: addressing inaccessible research. Lancet. 2014;383(9913):257-66.

21. World Medical Association. World Medical Association Declaration of Helsinki: ethical principles for medical research involving human subjects. JAMA. 2013;310(20):2191-4.

22. van Assen MA, van Aert RC, Nuijten MB, Wicherts $J M$. Why publishing everything is more effective than selective publishing of statistically significant results. PLoS One. 2014;9(1):e84896.
23. Durani P, Rimouche S, Ross G. 'How many plastic surgeons does it take to write a research article?' - Authorship proliferation in and internationalisation of the plastic surgery literature. J Plast Reconstr Aesthet Surg. 2007;60(8):956-7.

24. Denadai R, Samartine Junior H, Denadai R, Raposo-Amaral CE. The public recognizes plastic surgeons as leading experts in the treatment of congenital cleft and craniofacial anomalies. J Craniofac Surg. 2015;26(8):e684-9.

25. Carley S, Lecky F. Statistical consideration for research. Emerg Med J. 2003;20(3):258-62.

26. Song F, Loke $Y$, Hooper L. Why are medical and health-related studies not being published? A systematic review of reasons given by investigators. PLoS One. 2014;9(10):e110418.

27. Song D, Abedi N, Macadam S, Arneja JS. How many work hours are requisite to publish a manuscript? Plast Reconstr Surg Glob Open. 2013;1(1). pii:e9-10.

28. Rymer BC, Choa RM. A worldwide bibliometric analysis of published literature in plastic and reconstructive surgery. J Plast Reconstr Aesthet Surg. 2015;68(9):1304-8.

29. Zhang WJ, Ding $W$, Jiang $H$, Zhang YF, Zhang $\mathrm{JL}$. National representation in the plastic and reconstructive surgery literature: a bibliometric analysis of highly cited journals. Ann Plast Surg. 2013;70(2):231-4.

30. Smart RJ, Susarla SM, Kaban LB, Dodson TB. Factors associated with converting scientific abstracts to published manuscripts. J Craniofac Surg. 2013;24(1):66-70.

Received in: 16/10/2016

Accepted for publication: 03/11/2016

Conflict of interest: none.

Source of funding: none.

\section{Mailing address:}

Rafael Denadai

E-mail: denadai.rafael@hotmail.com rdenadaip@hotmail.com 